\title{
The Reform and Practice of the Teaching Model of Engineering Mathematics Based on the Construction of Teaching Resource Platform
}

\author{
Xiao-ping ZHANG ${ }^{1}$, Qian $\mathrm{GE}^{2,}{ }^{2}$, Xiu-zhen $\mathrm{LI}^{1}$ and Ming-tao $\mathrm{HU}^{2}$ \\ ${ }^{1}$ School of Science, Shandong Jianzhu University, Jinan, 250101, China \\ ${ }^{2}$ Shandong Education Press, Jinan, 250001, China
}

Keywords: Engineering mathematics, Teaching resource, Teaching model.

\begin{abstract}
In engineering colleges, mathematical teaching has many issues, such as the lack of application trainings and the unicity of teaching methods. It is necessary to study how to deal with the relationship between the teaching of mathematics and the cultivation of applied talents. Through the construction of teaching materials, mathematical experiments, network resources and other teaching resources, the course structure has been adjusted, the teaching process has been optimized and a new teaching model has been created. The new model integrates theory teaching, experimental teaching, extracurricular activities and interactive network teaching. The practice shows that this new model is effective in improving the overall quality of mathematics teaching and in improving the students' innovation and the ability to solve practical problems.
\end{abstract}

\section{Introduction}

Mathematics is not only the essential tool to solve the problems of engineering and other subjects, but also the basis for the development of many other disciplines. At the same time, it is very important in the cultivation of a person's mathematics quality, logical thinking, abstract thinking, space imagination, induction and comprehensive thinking quality and the way of thinking [1].

There are some disadvantages in the current university mathematics education curriculum, such as paying too much attention to the derivation process of the theories and too little attention to the mathematical thought and methods behind these theories, lack of the necessary training in the application of theories, teaching content being out of date, lack of new teaching resources, and single teaching method.

It is an important subject for the reform of mathematics teaching and curriculum building as to how to make full use of the rapid development of information and software technology to create new teaching resources, how to strengthen students' ability in applying mathematical theories and computer technology to practical problem-solving [2]. So starting from the ideology of modern education concepts and teaching philosophies, we explored the inherent connection between the training of applied innovative talents and the teaching of engineering mathematics, redefined the purpose, significance and process of mathematics teaching, furthered the reform of mathematics teaching, focused more on the construction of mathematics courses and enriched teaching resources. Through the construction of the teaching system and the teaching model, innovative mathematics teaching activities were carried out; the combination of theoretical teaching and practical application were promoted; the cultivation of application ability was strengthened; and the teaching quality has 
constantly improved. We actively sought to adapt to the new requirements for the cultivation of talents' quality brought about by the development of modern science and technology.

\section{Developing Teaching Resources and Building a Diversified Teaching Platform}

\section{Building Engineering Mathematics Curriculum and Writing Teaching Materials to Meet the Needs of The Development of Modern Science and Technology}

Curriculum construction is the center and link of all the aspects of teaching. For many years, we have taken the curriculum construction as the center, the development and application of the "mathematics experiment" as the key point, the supplementary teaching of practical teaching content and modern information technology as expansion, and the cultivation of teaching staff construction as the support. Outstanding results have been achieved through our long-term unremitting efforts.

We started writing the book Mathematics Experiment in 2000. The experimental teaching content has been constantly enriched and the teaching effect has been improved continuously after many years of research and accumulation as well as a continuous increase in the number of teaching examples. The textbook Mathematics Experiment has been reprinted several times, and was named the "Twelfth Five Year Plan" national planning textbook for higher education by The Ministry of Education [3]. At the same time, in order to adjust the mathematics curriculum to the requirements of the teaching reform and development, we have rewritten nine books on engineering mathematics, such as the Advanced Mathematics, Linear Algebra and Probability Theory and Mathematical Statistics. Added to the new teaching materials are models on engineering application, integrated into mathematical modeling and experiments, and well-matched with the corresponding digital curriculum resources. The digital resources consist of the following modules: guided preview, questions and answers, simulation and demonstration, knowledge expansion and self-test questions. By building these resources we have built a comprehensive teaching resources platform for engineering mathematics, and solved the problem of lack of engineering mathematics application examples that cannot be provided by traditional teaching materials.

\section{Constantly Enriching the Teaching Content and Improving the Construction of Experimental Courses}

In order to meet the needs of different majors as well as students' individual interest, make the content of mathematics experiment match the basic knowledge of mathematics, we have revised the basic requirements for the teaching of Mathematics Experiments and Mathematics Modeling by integrating in-class study with students' online autonomous learning under the guidance of teachers. A series of electronic teaching materials on practical application were constructed to match the corresponding content of public Mathematics Course's for engineering students in grade one and two. For example, to match the teaching materials related to Higher Mathematics calculation, theory and application, we have written Experimental Series I, which covers such content as computational experiments, mathematical simulation and application experiments, with the aim of cultivating students' practical ability [4] in the course of mathematics experiment, by integrating computation methods with computation experiments and abstract theory with simulation experiments. 


\section{Making Full Use of Modern Information Technology and Strengthening the Construction of Network Resources Platform}

We built a Mathematics Teaching Website in 2000. Through years of joint efforts by all mathematics teachers and by constantly enriching the teaching and learning materials, the function of the website has been widely expanded, and a full time and space, interactive, comprehensive, multi-media modeled teaching and learning resources platform has been established.

1) We are able to share quality teaching resources of our experienced math teachers by developing the exercise database of Advanced Mathematics, Linear Algebra and The Theory of Probability and Mathematical Statistics.

2) We have written companion books to Higher Mathematics, Linear Algebra and The Theory of Probability and Mathematical Statistics. These books feature summaries of the main content of each of the above courses, detailed explanations of typical difficult questions, as well as answers and analysis of synchronizing exercises related to these courses. We also compiled an E-book entitled Introduction to Mathematical Modeling, and several books titled Typical Difficult Problems \& Common Error Analysis for Higher Mathematics, Linear Algebra and Probability Theory and Mathematical Statistics respectively.

3) We developed an online examination questions database for students to do selftesting on Higher Mathematics, Linear Algebra and Probability Theory and Mathematical Statistics so that they can monitor and adjust their autonomous study accordingly.

4) In our teaching website, we created modules such as "mathematical modeling courseware", "selected collections of the national college mathematical modeling contest", "interesting Mathematical stories", "Teachers' guidance", etc.

5) We established a platform online for teachers to do research and to interact with students [5].

\section{Integrating Teacher Training and Nurturing with Teaching Reform Practice}

It is impossible to carry out teaching reform without well-qualified teachers. Therefore, we take measures to train and nurture our teachers. For example, by carrying out various kinds of teaching and researching activities on implementing new teaching methods and learning new teaching concepts and theories, we have updated the teachers education philosophy; by organizing teachers to collect typical mathematical cases and write teaching materials, we have changed the teaching model from pure instructions of theories into a combination of theory and application of theories for solving practical problems; by developing the multimedia teaching software and online teaching resources, teachers ability in using modern technology, and doing scientific research, has been greatly improved; by organizing activities of scientific innovation, teachers' ability for carrying out academic research has also been improved.

\section{Adjusting Course Structure, Optimizing the Teaching Process and Reforming Teaching Models}

With the support of our teaching resource and by adjusting course structure, optimizing the teaching process and reforming teaching models, we have changed the previous pure mathematical theories instruction teaching model into a diversified new teaching model featured by an integration of theory instruction, practical teaching, 
extracurricular creativities and online interactive teaching, adjusted courses' structure, optimized the teaching process and reformed teaching models. To be more specific:

Combining theory instruction with practical experiments. In order to provide corresponding practice in the application of mathematical theories and enhanced the experimental practical teaching of the Mathematics Curriculum. Our university is one of the earliest universities of its type to offer Mathematical Experiments and mathematical modeling as optional courses. As supplemental courses, we also have a series of lectures on Mathematical Software. In this way we have changed the traditional model of instructions only on mathematical theories [6,7].

Combining the mathematic major with other relevant majors. It is not uncommon for students majoring in math not to be able to apply their mathematical knowledge to the application of solving practical problems. For instance, in Physics and Mechanics, infinitesimal methods are often used to solve continuous variable problems and differential equation to analyze the related problems in biology and electricity. However, students often do not know what kind of mathematical knowledge should be applied to solve the problems. Therefore, we came up with some mini- projects based on frequently used mathematical knowledge in basic courses for math majors. Students have to finish these projects after class and the completion of these assignments are counted into their usual performance, which in turn counted towards their final GPA. In this way, we have enhanced the practical application of math and closely related the teaching of math to other majors.

Combing classroom instruction with scientific and technological innovation activities. Colorful extracurricular activities such as Mathematical Modeling Contest, College Student Mathematics Contest and Mathematical Culture Festival (which has so far been held for 10 sessions) are regularly organized. Students are encouraged to participate in math teachers' scientific research programs or various scientific and technological innovation activities initiated by enterprises and to write scientific research papers. Through the above activities, undergraduate students have received preliminary but very effective training on scientific research.

Combining traditional classroom teaching with interactive online teaching platforms. The advantages of the traditional classroom teaching are that teachers can provide detailed explanations and thorough analysis, and that great attention is paid to the communication and interaction between teachers and students. However, in the traditional classroom, the teaching effect is impacted by teachers having to take up too much time in blackboard-writing, lack of three-dimensional demonstrations and other restrictions. Online teaching resources platforms greatly enriched teaching materials and expanded teaching time and space, has become a strong support and effective supplement to traditional ways of teaching.

Meanwhile, in order to mobilize the students' initiatives in learning and to make a comprehensive evaluation of students' learning attitude and aptitude, we have changed the previous assessment methods into the " $1+1+X$ " model. The first " 1 " refers to students' usual performance, i.e. attendance, classroom performance and home assignments. The second "1" refers to student's final examination, which focuses on testing students' understanding of basic concepts, methods and comprehensive application of knowledge, rather than solving multifarious calculations and mathematical proof questions. The " $\mathrm{X}$ " refers to a term paper or experimental report the students have to submit at the end of the semester [8]. 


\section{Achievements}

Through years of reform and practice, our new model for teaching Engineering mathematics has made remarkable achievements. The overall teaching quality of mathematics has been improved, as can be seen from the increasing excellence rate of teachers of engineering mathematics. Moreover, a number of courses were titled Shandong provincial level of excellence courses, among which are Advanced Mathematics, Linear Algebra, Probability Theory and Mathematical Statistics. Besides, we have authored a series of teaching materials for engineering mathematics, of which Mathematics Experiment has been selected for the national "Twelfth Five Year" planned course book, and is widely used in many universities.

The new teaching model also stimulates students' interest in mathematics learning and helps to improve students' problem-solving ability by applying mathematical knowledge. As a result, the number of students winning prizes in College Mathematics Modeling Contest and College Mathematics Contest is growing every year. In addition, a variety of extra-curricular science $\&$ technology activities have become popular with students and achieved considerably good teaching effects.

Last but not least, our math teachers' ability in doing mathematics modeling and applying mathematical software have seen great progress and as a result, the overall qualities and research abilities have been improved. A strong team of highly qualified teachers has thus been built.

\section{Acknowledgement}

The teaching reform project "The reform and practice of the Teaching model of engineering mathematics based on the construction of teaching resources platform" won the first award of Shandong province teaching achievements. This research was financially supported by the teaching reform project of higher education in Shandong province (2012298).

\section{References}

[1] S.Y. Zhang, The thought, method and application of mathematics, Peking University Press, Beijing, 2003.

[2] The Higher Education Department of the Ministry of Education of the People's Republic of China, Research and demonstration of the research learning and cultivation of innovation ability, Higher Education Press, Beijing, 2010.

[3] X.Z. Li, Mathematics experiment, China Machine Press, Beijing, 2013.

[4] Z.X. Zhang, College Mathematics, 29(5) (2013) 7-12.

[5] G. Xu , R. Li, Studies in College Mathematics, 8(6) (2005) 51-53.

[6] X.Z. Li, Higher mathematics (for Arts), Higher Education Press, Beijing, 2014.

[7] X.Z. Li, Higher mathematics, Beijing University of Posts and Telecommunications Press, Beijing, 2010.

[8] Q. Ge and X.Z. Li, J. Shandong Jianzhu Uni., 28(1) (2013) 82-85. 